\title{
THE INFLUENCE OF THE SUBSTRATUM ON THE METAMORPHOSIS OF NOTOMASTUS LARVAE
}

\author{
By Douglas P. Wilson, M.Sc. \\ Naturalist at the Plymouth Laboratory
}

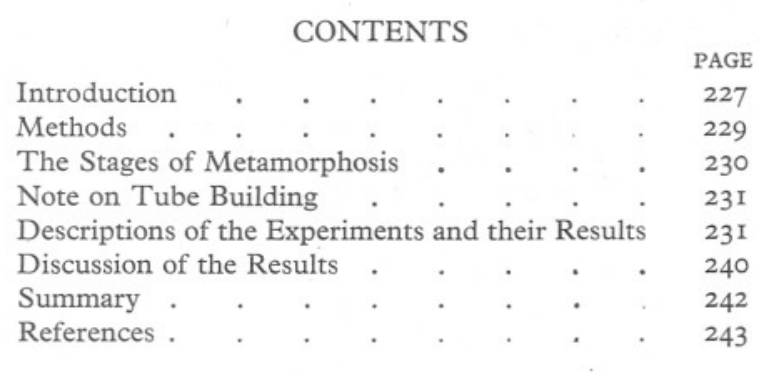

\section{INTRODUCTION}

Among the factors responsible for local distribution of the marine bottom fauna it is well known that the nature, particularly the grade, of the bottom deposit is all important. Mud, for instance, yields quite a different animal association from sand or gravel. Many, if not most, of the animals concerned have pelagic larvae, which drift with the plankton during early development, and the question at once arises how, when the time comes to metamorphose, larvae reach the kind of substratum to which their adult lives are suited.

It has been answered by supposing that, like seeds scattered by the wind, they take their chance of falling on to either barren or fruitful soil. Thus in a recent paper Yonge (1937, p. 699), while discussing the distribution of two closely allied species of Aporrhais, one of which lives in firm muddy gravel bottoms, the other in softer bottoms of fine mud, has suggested that "the survival of the young of the two species, after they descend at metamorphosis from the surface waters, must depend on the type of bottom on which they fall etc." If they drop on to the right kind of bottom they survive, if not they die.

Now this idea, which seems to have been accepted generally by many writers - unconsciously perhaps and not necessarily stated neatly and specifically as by Yonge-presupposes that metamorphosis takes place in mid-water and that after sinking to the bottom the young molluscs, worms, or whatever they may be are not able to rise up and swim again; they have no chance of getting away should the soil not be to their liking. Yet we know that often there is produced about the time of metamorphosis a creature that can both 
crawl and swim. Lebour, for example, has definitely recorded this (I93I-6) for veligers of the following species: Nassarius reticulatus, $N$. incrassatus, Philbertia gracilis, $P$. linearis, Erato voluta, Rissoa parva, Natica maculata, $N$. catena. Such a stage doubtless occurs in many other molluscs, as well as in the development of species belonging to other phyla, and it is likely that if larvae in this stage strike an unsuitable substratum they will rise and swim away, drifting perhaps with the currents to new ground. Even if they possess this ability for a few days only their chances of ultimately reaching a satisfactory soil are enormously increased compared with those of inert seeds, which once fallen cannot move of their own volition.

The rate at which a species develops is generally considered to be fairly constant at a given temperature within the normal range, though variations do occur, depending doubtless on such factors as the relative amounts of food individual larvae obtain. One might expect that metamorphosis would take place when a fairly constant and predictable interval of time had elapsed after fertilization, in other words that it is a phase of development which must supervene once a definite stage has been reached. If this were so the risks attendant on settlement would be greater than they probably are; the larvae would have to strike the right grade at a definite instant in their development, particularly so if the transition from a swimming organism to one that can only burrow or crawl be at all rapid. Cataclysmically metamorphosing larvae, however, can probably undergo the change at any convenient moment during a period of several days at least; I have already shown that this is true for Owenia fusiformis (Wilson, 1932). Species with a more gradual metamorphosis may be able to delay the event for a long period as can Scolecolepis fuliginosa (Day \& Wilson, 1934). With cultures of Branchiomma vesiculosum (Wilson, I936) a fairly suitable substratum was available all the while, but there was considerable variation in the time of settling. In this instance, however, we do not know whether each larva metamorphosed as soon as it was able, or whether, as seems probable, some delayed for a time because conditions in a bowl are not ideal.

The investigation of problems concerning the settlement of larvae is of no little importance in the study of distribution and may be of economic importance, as in the oyster and wood-boring organisms. Among the more outstanding papers which have already appeared may be mentioned that of Grave \& Woodbridge (1924) on the influence of light and shade in directing the larvae of Botryllus to a resting place, Visscher's work (1928) and that by Visscher \& Luce (1928) on the settling of Balanus cyprids, and the paper by Prytherch (1934) dealing with the surprising role of copper in the settling of the American oyster. Davis (1923), from a somewhat different aspect, has discussed the influence of currents on the dispersal and chances of settling of the larvae of Spisula, a staple food of the plaice. On the whole, however, little has been accomplished, and our knowledge of the reactions of larvae to the grade of the bottom deposit is especially scanty. We have also very few data on the ability 
or otherwise of larvae to postpone metamorphosis until a favourable substratum is reached.

With the intention of continuing investigations along the lines indicated at the end of the last paragraph it was decided to test the larvae of Notomastus latericeus Sars. The development of this species has already been described (Wilson, I933); fertilizations are readily obtainable and the larvae easily reared. They seemed to be specially suitable for the purpose in that they do not feed until some days after metamorphosis, and there are therefore no complications due to introduced food materials. The adults, moreover, are generally confined to mud and very muddy sand, although they are occasionally to be found in somewhat cleaner situations. They do not occur in clean coarse sand or gravel. Pelagic life is, however, rather short, so any postponement of metamorphosis might be of very brief duration. The larvae are also very small and might be difficult to find in the mud after settling. As it turned out this last was by far the greatest difficulty encountered.

\section{MeTHODS}

Adult worms were dug out of the mud at the Salstone, Salcombe, and fertilizations were made as described in a previous paper (Wilson, I933). Larvae were generally reared in a plunger-jar for a few days before the experiments were set up. The small dishes used in these experiments were covered with glass plates and stood on a bench close together so that lighting and temperature conditions should be as uniform as possible throughout each experiment. Details of the various dishes are given below. The sea water used was taken from well outside the breakwater and was invariably passed through a Berkefeld filter. All gravels, sands and muds were sterilized by boiling in fresh water and then thoroughly washed with repeated changes of filtered sea water.

The mud used was that in which the adults were found. It contained a fairly high proportion of sand grains which varied in size between about 40 and $2000 \mu$. The main body consisted of flocculent matter from very fine particles to small masses of soft material. In the dishes it settled a little unnaturally in that the finest particles deposited last of all to form a film over the surface. In nature the surface showed a higher proportion of exposed sand grains, the finest particles evidently washing away at the surface. I do not think, however, that this difference had any real effect on the settling of the larvae. The clean sand had a more uniform particle size than the mud: the greatest diameter of the grains generally lay between Ioo and $500 \mu$, very few were smaller or larger than this, while the average size worked out at $243 \mu$. There was no contained flocculent matter. The gravel, a moderately coarse clean gravel of shell fragments from deep water, was well washed to remove all fine particles. The remaining fragments varied in size from about 500 to $8000 \mu$ along their greatest lengths: the average was approximately $3000 \mu$.

The larvae when they settled were about $300 \mu$ long, and as already men- 
tioned the chief difficulty was to find them in the soils. Searching the latter was a tedious process tiring to the eyes. A little mud or sand would be removed from the experimental dish and dispersed under water in a glass trough on the stage of a binocular dissecting microscope. As the newly settled larvae were smaller than many of the sand grains they were difficult to detect until they moved. They were most easily found in the clean sand, especially when they had formed their first rough tubes. In the mud the great variety of debris tended to conceal even these tubes. Settled larvae were also very difficult to find in the gravel where the fragments were so much larger than they. If after searching a dish intensively for $\mathrm{I}-2 \mathrm{hr}$. the majority of the larvae or worms had been found, and their various conditions noted, the result was considered sufficiently good for the purpose. The last few were naturally the most difficult to find, and their condition, whatever it was, would not upset the main conclusion. When larvae were not found it must not be assumed that they had died, because during the first week or Io days the death-rate of this species, even in crowded finger-bowls, was negligible. The larvae are very hardy and have been known to survive for many hours after severe injuries.

On account of the time taken to search one dish thoroughly it was not usually possible to examine all of them properly on any one day, although it could quickly be seen whether any larvae were still swimming or not, and this much at least would be recorded.

\section{The Stages of Metamorphosis}

For our present purpose metamorphosis can be divided conveniently into three stages. In the first the larva attaches itself to the substratum by its posterior end, gland cells in the pygidium producing some sticky substance which enables it to do this. At first the adhesion is slight and the larva readily swims away if disturbed; it may break away of its own accord, as often happened in the clean controls. The cilia of both prototroch and telotroch beat strongly, there are no signs of their coming disappearance. This, the "sticky stage", is represented in the tables by the letter $b$, letter $a$ denoting freely swimming larvae.

The second stage begins when prototroch and telotroch start to disappear and lasts until metamorphosis is practically completed. This stage is denoted by the letter $c$.

In the third stage the worms have completed metamorphosis, either just finished or any time afterwards; they are indicated by the letter $d$.

This classification is on very broad lines, but it is ample for the purpose and any finer divisions are unnecessary. It should be noted, however, that metamorphosis is considered as being completed with the final disappearance of prototroch and telotroch. No attention is paid to the neurotroch which is got rid of a little later; it was not practicable to determine the condition of that organ without considerable extra work for which time was not available. 


\section{Note ON TUBE BuILDING}

In my I933 paper no mention is made of the tube these worms build when they first settle down; they were not at that time specially provided with mud or sand as in these experiments. The metamorphosing worm quite early sticks together sand grains or debris into the form of a rough fragile tube. The process begins at the time when the larva first anchors itself by the pygidial glands, and the grains are soon loosely knit into the form of a tube. If the tube is disturbed or broken shortly after its formation the larva will release itself and swim away. Such larvae are always recorded in the tabulated results as stage $b$. The tubes are quite short at first, during the first day or two about a millimetre long and half that in width. Later they reach lengths of several millimetres. The mucus used in the construction of the tubes is probably secreted by ectodermal glands of the body wall and of the pygidium, but the point has not been definitely settled. Sometimes the worms are found out of their tubes crawling freely in the sand or mud.

\section{DESCRIPTIONS OF THE EXPERIMENTS AND THEIR RESULTS}

The first set of experiments was made with larvae from eggs fertilized on May 2 1935. The larvae were reared in a plunger-jar until May 7 , when the experiments were begun.

Exp. I. Small flat-bottomed glass dishes with sloping sides and an internal diameter on the bottom of about $4 \mathrm{~cm}$. were used. About I2 c.c. of sea water were poured into each and, except in the two clean controls, the bottom was completely covered with sand or mud to a depth of I or $2 \mathrm{~mm}$. Two dishes contained Salstone mud, one clean well-washed sand, and one, $E$, finer sand slightly overgrown with diatoms and therefore somewhat slimy. Twenty swimming larvae were put into each dish.

Table I indicates the results; it will be seen that the larvae rapidly disappeared in the dishes containing mud or sand while still swimming in the clean controls. The fine flocculent mud that formed a smooth surface layer in mud dishes $B^{1}$ and $B^{2}$ was on the second day marked with several tiny holes where the larvae may have crawled into it. In each dish on that day two larvae were observed on the mud surface; they were in what I have called the "sticky stage". A few similar ones were seen on the surface of the sand in dish $D$, where the majority were still swimming freely. An attempt was made to find those which had disappeared, but it proved a hopeless task in view of the relatively large quantity of mud and sand present. Another search 2 days later also failed to reveal any of them. In the light of further experience it can, however, be said that it is extremely probable that they were alive in the soils and undergoing metamorphosis.

On the third day three much smaller dishes were prepared and five larvae from clean control $A^{1}$ put into each. One of these dishes contained a little 
mud, one a little sand, and the third was left clean. By the next day the development of the larvae in the mud and sand dishes showed a definite advance over those in the controls.

\section{TABLE I}

(Exp. I. Fertilization on May 2 I935)

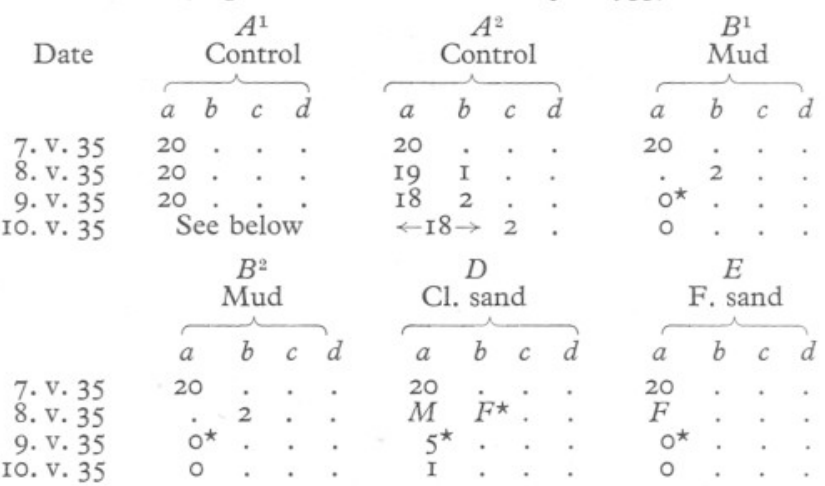

Subsidiary experiment with larvae from control $A^{1}$

\begin{tabular}{|c|c|c|c|c|c|c|c|c|c|c|c|}
\hline \multirow{2}{*}{ Date } & \multicolumn{2}{|c|}{$\begin{array}{c}A^{1} \\
\text { Control }\end{array}$} & \multicolumn{3}{|c|}{ Clean } & \multicolumn{3}{|c|}{ Mud } & \multicolumn{3}{|c|}{ Sand } \\
\hline & $\begin{array}{ll}a b \\
a\end{array}$ & $c d$ & $a$ & $b$ & $c d$ & $a$ & $b$ & $c d$ & . & $b$ & $c \quad d$ \\
\hline $\begin{array}{l}\text { 9. v. } 35 \\
\text { o. v. } 35\end{array}$ & $\stackrel{5}{<-5 \rightarrow}$ & $: \quad:$ & $\begin{array}{l}5 \\
4\end{array}$ & $\dot{\mathbf{I}}$ & $: \quad$. & 5 & . & $2 \dot{3}$ & 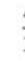 & . & $\dot{I} \quad \dot{2}$ \\
\hline
\end{tabular}

Explanation of the Symbols used in the Tables

$a$, swimming larvae.

$b$, larvae in "sticky stage".

$c$, metamorphosing larvae.

$d$, young worms after metamorphosis.

$F$, few,

$M$, majority.

$N$, a fairly large number less than a majority.

All larvae found are recorded. An asterisk denotes that the dish was examined to determine the number of larvae swimming and whether any were visible on the surface of the soil, but that the soil itself was not searched. If the dish was not examined at all a dot appears in all four columns.

Exp. 2. This ran concurrently with Exp. I. Smaller flat-bottomed glass dishes with vertical sides and an internal diameter of about $3 \mathrm{~cm}$. were used. Each contained about 8 c.c. of sea water, and less soil than in the preceding experiment. Two additional soils were employed, one of clean coarse gravel and one of very fine flocculent mud. As before twenty swimming larvae were placed in each dish.

An examination of the results summarized in Table II shows definitely that by the third day larvae in the dishes containing bottom soils were on the whole advanced in development over those in the clean controls. This is clearly seen if the records on May 9 for thorough searches of the fine sand $\operatorname{dish} E$ and the mud dish $B^{1}$ be compared with those of controls $A^{1}$ and $A^{2}$. Unfortunately there was too much soil to make a thorough search of all the dishes practicable, 
but the results that were obtained from short searches of the clean sand $D$ and flocculent mud $F$ are, as far as they go, confirmatory evidence.

TABLE II

(Exp. 2. Fertilization on May 2 1935)

\begin{tabular}{|c|c|c|c|c|c|c|c|c|c|c|c|c|c|c|}
\hline \multirow{5}{*}{$\begin{array}{l}\text { Date } \\
\\
\text { 7.v. } 35 \\
\text { 8. v. } 35 \\
\text { 9. v. } 35 \\
\text { IO. v. } 35\end{array}$} & \multicolumn{4}{|c|}{$\begin{array}{c}A^{1} \\
\text { Control }\end{array}$} & \multicolumn{4}{|c|}{$\begin{array}{c}A^{2} \\
\text { Control }\end{array}$} & \multicolumn{3}{|c|}{$\begin{array}{c}B^{1} \\
\text { Mud }\end{array}$} & \multicolumn{3}{|c|}{$\begin{array}{c}B^{2} \\
\text { Mud }\end{array}$} \\
\hline & $a$ & $b$ & $c c$ & $d$ & a & $b$ & $c$ & $d$ & $a$ & $\begin{array}{ll}b & c\end{array}$ & $d$ & $a$ & $\begin{array}{ll}b & c\end{array}$ & $d$ \\
\hline & 20 & . & . & . & 20 & . & . & . & 20 &.$\quad$. & . & 20 & $i_{\star \star} \cdot$ & . \\
\hline & $\begin{array}{l}19 \\
14\end{array}$ & $\begin{array}{l}1 \\
6\end{array}$ & . & . & $\begin{array}{l}18 \\
15\end{array}$ & $\begin{array}{l}2 \\
3 \\
\end{array}$ & $\dot{2}$ & . & $\begin{array}{l}1 \\
\cdot\end{array}$ & $\dot{3} \mathrm{rit}$ & $i$ & $\dot{o}^{\star}$ &. & : \\
\hline & $F$ & & & . & & $\bar{M}$ & & . & o* $^{\star}$ & . & . & $0^{\star}$ & . . & . \\
\hline & & $\underset{\text { Gra }}{C}$ & & & & $\begin{array}{r}D \\
\mathrm{Cl} . \mathrm{s}\end{array}$ & and & & & $\begin{array}{c}E \\
\text { F. sand }\end{array}$ & & & $\begin{array}{c}F \\
\text { Fl. mud }\end{array}$ & \\
\hline & $a$ & $b$ & $c$ & $d$ & $a$ & $b$ & $c$ & $d$ & $a$ & $b$ & $d$ & $a$ & $c$ & $d$ \\
\hline $\begin{array}{l}\text { 7.v. } 35 \\
\text { 8.v. } 35\end{array}$ & $\begin{array}{l}20 \\
F\end{array}$ & . & $\cdot$ & . & $\begin{array}{c}20 \\
F\end{array}$ & . & . & . & 20 & . & . & 20 & ix $\cdot$ & . \\
\hline $\begin{array}{l}0 . \mathrm{v} \text {. } \\
9 . \mathrm{v} .\end{array}$ & F & : & $\dot{i}$ & i & $F$ & $\dot{I}$ & $:$ & 6 & $F$ & - & & $\cdot$ & $2^{\star}{ }^{\star}$ & 5 \\
\hline o. v. 35 & ${ }^{\circ}$ & . & & & & . & $\dot{I^{*}}$ & . & $0^{\star}$ * &.$\quad 1$ & 11. & o* & . & ? \\
\hline
\end{tabular}

The preceding experiments having suggested that there does exist, in this species, a relation between metamorphosis and the substratum, it was decided that it would be worth while obtaining further data. Accordingly another fertilization was made on May 20 I935 and the following experiments performed. They were begun 3 days after fertilization instead of 5. The larvae were then at the stage shown in pl. I, fig. 2 of my 1933 paper, definitely earlier in development than those used in the first two experiments.

Exp. 3. The dishes used were the same as those in Exp. I. Rather less soil was put into them, but the quantity was still relatively large. The fine and not very clean sand of dish $E$ was omitted, otherwise the soils were of the same grades as before, although newly washed quantities were used. Fifty swimming larvae were put into each dish.

The amounts of soil were too large to search properly. It had been hoped that the bigger number of larvae would result in a few, at least, being found quickly, but this was not so. However, the experiment shows on the whole a quick descent into the mud and later into the sand, while a careful search of the sand in dish $D$ on May 29 revealed that over half the worms, in fact all those found, had metamorphosed, while considerably fewer than half had metamorphosed in the controls. A search of a little of the mud in dish $B^{1}$, on the previous day, had yielded two metamorphosed worms at a time when none had metamorphosed in the controls. Doubtless other metamorphosed ones were present in the larger portion of the mud which was not searched thoroughly. Incidentally it may be mentioned that as late as September 4 three well-grown young worms were found in this dish.

The result on the gravel is a little difficult to interpret. The particles were so large that the larvae could swim freely in the interstices-as they were 
observed to do in the 1937 experiments-and some of them probably did this during the first three or four days of the experiment. At the time a note was made suggesting the possibility. Later one metamorphosed worm was seen crawling on the side of the dish but the fate of the other larvae is not known.

TABLE III

(Exp. 3. Fertilization on May 20 1935)

Date
23. v. 35
24. v. 35
25. v. 35
26. v. 35
27. v. 35
28. v. 35
29. v. 35
30. v. 35
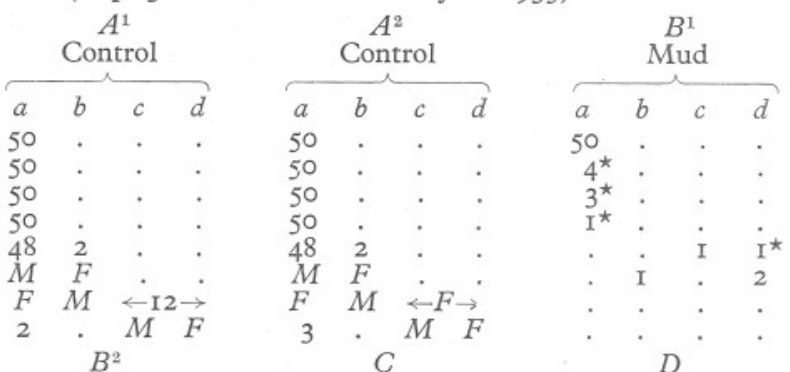

\begin{tabular}{|c|c|}
\hline & \multirow{2}{*}{$b$} \\
\hline 50. & \\
\hline \multicolumn{2}{|c|}{0.} \\
\hline \multicolumn{2}{|c|}{$\begin{array}{ll}0 & : \\
0 & : \\
0 & :\end{array}$} \\
\hline & $8 \quad 2$ \\
\hline & $\begin{array}{l}F \\
M\end{array}$ \\
\hline
\end{tabular}
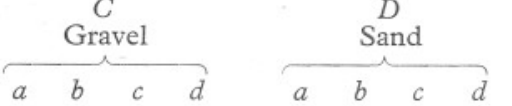

23. v. 35

24. v. 35

25. v. 35

26. v. 35

27. v. 35

28. v. 35

29. v. 35

30. v. 35

Mud

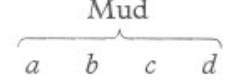

$\begin{array}{llll}50 & \cdot & \cdot & \cdot \\ \mathrm{I} 2^{\star} & \cdot & \cdot & \cdot \\ \mathrm{I} 2 & I^{\star} & \cdot & \cdot \\ \mathrm{I} 4^{\star} & \cdot & \cdot & \cdot \\ \mathrm{O}^{\star} & \cdot & \cdot & \cdot \\ \mathrm{O}^{\star} & \cdot & \cdot & \cdot \\ \cdot & \cdot & \cdot & \cdot \\ \cdot & \cdot & \cdot & \cdot\end{array}$

$\begin{array}{llll}50 & \cdot & \cdot & \cdot \\ 44^{\star} & \cdot & \cdot & \cdot \\ 26^{\star} & \cdot & \cdot & \cdot \\ N^{\star} & \cdot & \cdot & \cdot \\ 9 & \cdot & \cdot & \cdot \\ 0^{\star} & \cdot & \cdot & \cdot \\ \cdot & \cdot & \cdot & \cdot \\ \cdot & \cdot & \cdot & \cdot\end{array}$

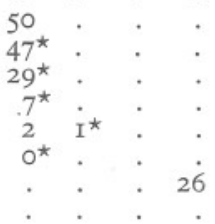

Exp. 4. The small dishes of Exp. 2 were employed here. The control and mud dishes were not duplicated and less soil was used than before; it was thus possible to search more thoroughly, although as the experiment ran concurrently with Exps. 3 and 5 all the time could not be spent on it.

This experiment gave a very definite result. There was still too much mud to be satisfactory, but a search of the sand dish $D$ yielded, on May 27, ten fully metamorphosed worms at a time when in the control none had properly started and all but two were still swimming freely. The count made 2 days later should also be noted. The relatively quick disappearance of swimming larvae in the mud dish is again seen.

\section{TABLE IV}

\begin{tabular}{|c|c|c|c|c|c|c|c|c|c|c|c|c|c|c|c|}
\hline \multirow[t]{2}{*}{ Date } & \multicolumn{4}{|c|}{$\begin{array}{c}A \\
\text { Control }\end{array}$} & \multicolumn{4}{|c|}{$\stackrel{B}{B}$} & \multicolumn{4}{|c|}{$\begin{array}{c}C \\
\text { Gravel }\end{array}$} & \multicolumn{3}{|c|}{$\begin{array}{c}D \\
\text { Sand }\end{array}$} \\
\hline & $a$ & $b$ & $c$ & $d$ & $a$ & $b$ & $c$ & $d$ & $a$ & $b$ & $c$ & $d$ & $a$ & $b$ & $c$ \\
\hline $23 \cdot v \cdot 35$ & 20 & . & . & . & 20 & . & . & . & 20 & . & . & . & 20 & . & . \\
\hline 24. v. 35 & 20 & . & . & . & 6 & 2 & . & . & 20 & . & . & . & 20 & . & . \\
\hline $25 . v \cdot 35$ & 20 & . & . & . & $6^{\star}$ & . & . & . & $15^{\star}$ & . & . & . & $19^{\star}$ & . & - \\
\hline 26. v. 35 & 20 & . & . & . & $6^{\star}$ & . & . & . & $N^{\star}$ & . & . & . & $7^{\star}$ & . & .. \\
\hline $27 \cdot v \cdot 35$ & I8 & 2 & . & . & $\cdot$ & I & $\dot{r}$ & $\dot{x}$ & $7^{\star}$ & . & . & . & I & . & . 10 \\
\hline 28 . v. 35 & M & $F$ & : & . & . & . & I & I & $I^{\star}$ & . & . & . & $0^{\star}$ & : & . \\
\hline $29 \cdot v \cdot 35$ & I4 & 3 & 3 & . & - & . & . & . & . & . & . & . & . & I & - I3 \\
\hline
\end{tabular}


Exp. 5. This was a duplication of Exp. 4 with the exception that it was kept in the dark. It ran concurrently. If Table $\mathrm{V}$, recording the results, be compared with Table IV, one striking difference will be noticed. In the present series the majority of the larvae in the mud dish continued to swim freely for some days longer than they did in Exp. 4, although for not so long as in the control, where incidentally most of the larvae metamorphosed a little sooner than in the corresponding control of Exp. 4. On other points the experiment is inconclusive, lack of time prevented thorough searches being made.

This apparent difference in behaviour between larvae kept in the light and others kept in the dark immediately led to the setting up of the following experiment designed to test this behaviour.

\section{TABLE V}

(Exp. 5. Fertilization on May 20 1935)

\begin{tabular}{|c|c|c|c|c|c|c|c|c|c|c|c|c|c|c|c|}
\hline \multirow[t]{2}{*}{ Date } & \multicolumn{4}{|c|}{$\begin{array}{c}A \\
\text { Control }\end{array}$} & \multicolumn{4}{|c|}{$\stackrel{B}{\mathrm{Mud}}$} & \multicolumn{3}{|c|}{$\begin{array}{c}C \\
\text { Gravel }\end{array}$} & & \multicolumn{3}{|c|}{$\begin{array}{c}D \\
\text { Sand }\end{array}$} \\
\hline & $a$ & $b$ & $c$ & $d$ & $a$ & $b$ & $c$ & $d$ & $a$ & $b$ & $c$ & $d$ & $a$ & $b$ & $c$ \\
\hline 3. v. 3 & 20 & . & . & . & 20 & . & . & . & 20 & . & . & . & 20 & . & . \\
\hline r & 20 & . & . & . & $17^{\star}$ & . & . & . & 20 & . & . & . & 20 & . & . \\
\hline & 20 & . & . & . & $16^{\star}$ & . & . & . & $19^{\star}$ & . & . & . & 20 & & . \\
\hline 26. v. 35 & I8 & 2 & . & . & $\mathrm{II}^{\star}$ & . & . & . & $F^{\star}$ & . & . & . & & $2^{\star}$ & - \\
\hline $\begin{array}{l}27 . v \cdot 35 \\
29 . v \cdot 35\end{array}$ & I6 & 2 & I & I & $4^{\star}$ & . & . & . & $3^{\star}$ & . & . & . & & . & - \\
\hline $\begin{array}{r}\text { 29. v. } 35 \\
\text { I. vi. } 35\end{array}$ & : & : & $F$ & M & $0^{\star}$ & : & & $\dot{4}$ & $0^{\star}$ & $\therefore$ & . & : & & & : \\
\hline
\end{tabular}

Exp. 6. Two dishes, both containing mud, were prepared and thirty swimming larvae put into each; one was kept in the dark and the other placed alongside the dishes of Exp. 4. Table VI records the result: no significant difference was observed between the two lots of larvae; on the other hand, the majority of both continued to swim I day longer than those in the mud dish of Exp. 4, but for not quite so long as those in the mud dish of Exp. 5. Perhaps these small variations in behaviour as well as the greater contrast between Exps. 4 and 5 are only a degree more striking than the difference that occurred between the mud dishes $B^{1}$ and $B^{2}$ of Exp. 3. It will be remembered that all these larvae were from the same original culture.

\section{TABLE VI}

(Exp. 6. Fertilization on May 20 1935)

\begin{tabular}{|c|c|c|c|c|c|c|c|c|c|c|c|c|}
\hline \multirow[t]{2}{*}{ Date } & \multicolumn{3}{|c|}{ In light } & \multicolumn{3}{|c|}{ In dark } & \multirow[t]{2}{*}{ Date } & \multicolumn{2}{|c|}{ In light } & \multicolumn{3}{|c|}{ In dark } \\
\hline & $a$ & $c$ & $d$ & $a b$ & $c$ & $d$ & & $a b$ & $c$ & $a \quad b$ & $c$ & $d$ \\
\hline 24. v. 35 & 30. & - & - & 30. & . & . & 27. v. 35 & $0^{\star}$. & . & $0^{\star \star}$. & . & . \\
\hline $\begin{array}{l}25 \cdot v \cdot 35 \\
26 . v \cdot 35\end{array}$ & $\begin{array}{r}19^{\star} . \\
7^{\star} .\end{array}$ & . & . & $\begin{array}{r}{ }^{1} 6^{\star} \\
5^{\star} .\end{array}$ & . & $\dot{.}$ & $\begin{array}{l}29 \cdot v \cdot 35 \\
31 . v \cdot 35\end{array}$ & $\begin{array}{l}0^{*} . \\
.\end{array}$ & I $\dot{7}$ & $\begin{array}{l}0^{x} . \\
.\end{array}$ & . & . \\
\hline
\end{tabular}

While the foregoing experiments indicated in a general way that larvae of Notomastus metamorphose earlier when in contact with a suitable bottom soil 
than when retained in clean glass vessels, they were not, in my opinion, entirely satisfactory. A sufficiently high proportion of metamorphosed worms had not been found, particularly in the mud dishes, and it was felt that, in order to show conclusively that the larvae had not merely been entrapped, smothered and killed in the mud, it would be necessary to demonstrate the presence alive of at least the majority of the young worms after metamorphosis. Accordingly it was decided to repeat the experiments and in the light of experience to improve the technique. The opportunity occurred in May 1937. In these later experiments less mud, sand, and gravel was used in each dish and this, together with superior optical equipment for conducting the search, yielded much better results.

On May Io 1937 mature Notomastus were obtained at Salcombe and a fertilization was made in Plymouth the same evening. On the following day most of the larvae were put into a plunger-jar, but some hundreds were kept in a clean finger-bowl. On May I4 the following two experiments ( 7 and 8) were begun, using larvae from the plunger-jar.

Exp. 7. Small glass dishes similar to those used in Exp. 2 were employed here. Only a little sand or mud, barely sufficient to cover the bottom in a very thin layer when evenly spread out, was introduced; it was, however, heaped around the sides, leaving some of the glass of the bottom exposed. On the second day a dish, $B^{3}$, containing a still smaller quantity of mud was added. In this instance the amount was too small to stay in a heap, it spread out and nowhere was there depth sufficient for a larva to bury itself. Twenty swimming larvae were put into each dish. The results are recorded in Table VII.

On May I7, the fourth day of the experiment, the first noteworthy result was obtained, although on the preceding two days there had been definite indications. In the clean sand dish $D$ eleven metamorphosed worms were found together with one undergoing metamorphosis; none was swimming. In the clean controls all were swimming freely except one larva which was very lightly stuck by its tail end to the bottom; when released with a gentle squirt of water it swam at once. Next day a search of the mud dish $B^{2}$ recovered from the mud fourteen metamorphosed worms and two metamorphosing. In the controls the great majority were still actively swimming, and the few that were lightly stuck to the bottom had not begun to metamorphose but swam like the others when gently disturbed with a pipette. The evidence on this day, May I8, is quite conclusive, the majority of the larvae in mud dish $B^{2}$ and sand dish $D$ had metamorphosed, while those of the same age in the controls had not begun. During succeeding days metamorphosis in the controls was very slow, so that even as late as May 20 when mud dish $B^{1}$ was searched the lag in their development was striking. Moreover, the worms in the controls were not as healthy as those in the soils.

The result in dish $B^{3}$ with very little mud was most interesting. The delay in metamorphosis during the first few days was almost as great as in the clean controls, but the larvae finally metamorphosed normally and were 
in excellent health on May 24 when those in the controls were showing signs of failing.

The larvae in the clean gravel dish $C$ followed, in general, the course taken by those in the controls. The majority continued to swim for several days, often in the interstices among the heaped gravel fragments. When they did finally metamorphose they gradually became unhealthy.

Exp. 8. The dishes in this experiment were glass funnels of maximum diameter of about $8 \mathrm{~cm}$. After careful cleaning the stems were blocked with a filling of paraffin wax and the funnels were then soaked in distilled water followed by sea water. They were supported in glass jars whose mouths were a little smaller in diameter than those of the funnels; the greater part of each funnel was thus inside its jar. Black paper was tied around the latter to ensure that the funnel would be lit only from above, as the sea bottom is illuminated in nature. Each funnel was partially filled with about 30 c.c. of filtered sea water and covered with a glass plate to keep out the dust. A sheet of white paper laid on top cut off the main strength of the light.

Funnels were chosen because they enabled a relatively large volume of water to be used in conjunction with very little bottom soil, for the latter would sink into the apex at the bottom, where larvae would also tend to collect whenever they swam downwards. On the whole the device was very satisfactory.

As usual two clean controls and two mud vessels were included together with one containing clean sand and one clean gravel. Twenty larvae were put into each and the experiment ran concurrently with Exp. 7, and as in this a third mud vessel with a very small quantity of mud was added on the second day.

On account of their shape the funnels were more difficult to examine than the glass dishes; they were not at all easy to search with the binocular microscope, and a simple hand-lens gave too low a magnification to be really useful. Hence even in the clean controls larvae were occasionally missed. Although the figures are not quite so complete as for Exp. 7 the result is none the less definite. An early descent into the mud was clearly indicated, and a little later into the sand. From a study of Table VIII it is obvious too that metamorphosis took place sooner in the mud and sand than in the gravel or the controls. Again, too, the health of those in all three mud vessels and in the sand was much better on May 27 and 28 than was that of the worms in the controls and in the gravel. These latter were in poor condition.

Mud vessel $B^{3}$ was extremely interesting in comparison with the similar dish in Exp. 7; the larvae stopped swimming almost as rapidly as in the funnels with much more mud. The reason appears to be that whereas in Exp. 7 the very small quantity of mud was scattered thinly over a wide area, in the present experiment the same quantity was gathered together in a small depression in the middle of the wax plug and the larvae could bury themselves in it.

Exp. 9. This was designed to test the results obtained with vessels $B^{3}$ of Exps. 7 and 8, where it seemed that a very little mud would have less effect 


\section{TABLE VII}

(Exp. 7. Fertilization on May Io 1937)

\begin{tabular}{|c|c|c|c|c|}
\hline \multirow[t]{2}{*}{ Date } & \multicolumn{4}{|c|}{$A^{1}$} \\
\hline & $a$ & $b$ & $c$ & $d$ \\
\hline I4. v. 37 & 20 & . & . & . \\
\hline I5. v. 37 & 20 & . & . & . \\
\hline I6. v. 37 & I9 & I & . & . \\
\hline I7. v. 37 & 20 & . & . & . \\
\hline I8. v. 37 & I9t & I & . & . \\
\hline I9. v. 37 & 3 & 4 & I & . \\
\hline 20. v. 37 & . & 6 & I & I \\
\hline 2I. v. 37 & & & 5 & 3 \\
\hline $\begin{array}{l}\text { 22. v. } 37 \\
24 \text {. v. } 37\end{array}$ & $\begin{array}{l}\text { Un } \\
\text { Dead }\end{array}$ & a & alth & ing \\
\hline 26. v. 37 & & & & \\
\hline
\end{tabular}

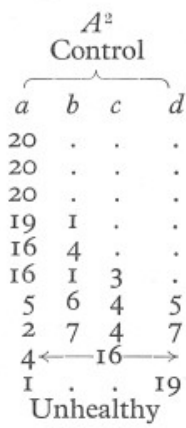

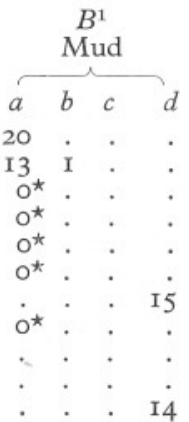

† I2 larvae preserved.
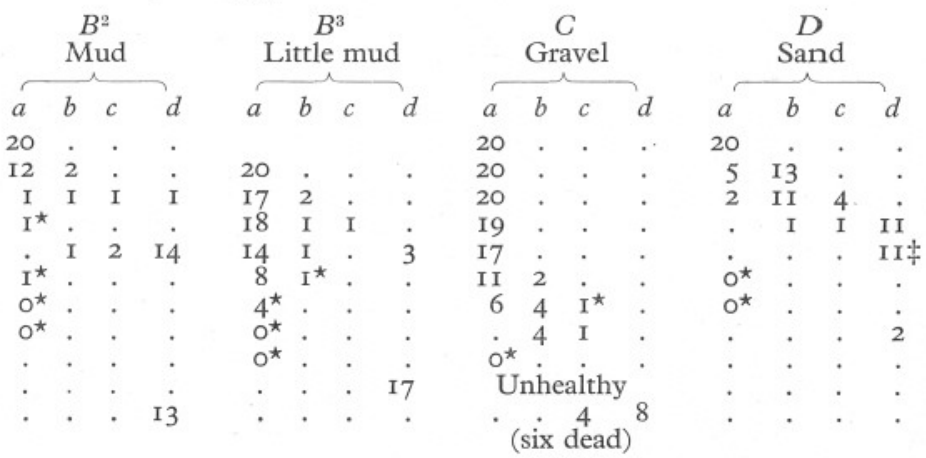

‡ II worms preserved.

\section{TABle VIII}

\section{Date}

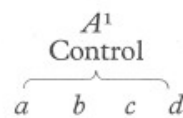

I4. v. 37

I5. v. 37

I6. v. 37

I 7 . v. 37

I8. v. 37

I9. v. 37

20. v. 37

2I. v. 37

27. v. 37

28. v. 37

\begin{tabular}{|c|c|c|}
\hline 20 & . & . \\
\hline & . & . \\
\hline I9 & . & . \\
\hline I8 & . & . \\
\hline & . & . \\
\hline I3 & 4 & . \\
\hline & . & . \\
\hline & I4 & . \\
\hline & & \\
\hline
\end{tabular}

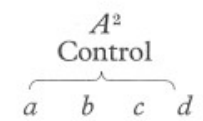

20

(2)

20

I9

I4

$\dot{M} \dot{M}$
(mainly
unhealthy)
(Exp. 8. Fertilization May Io I937)
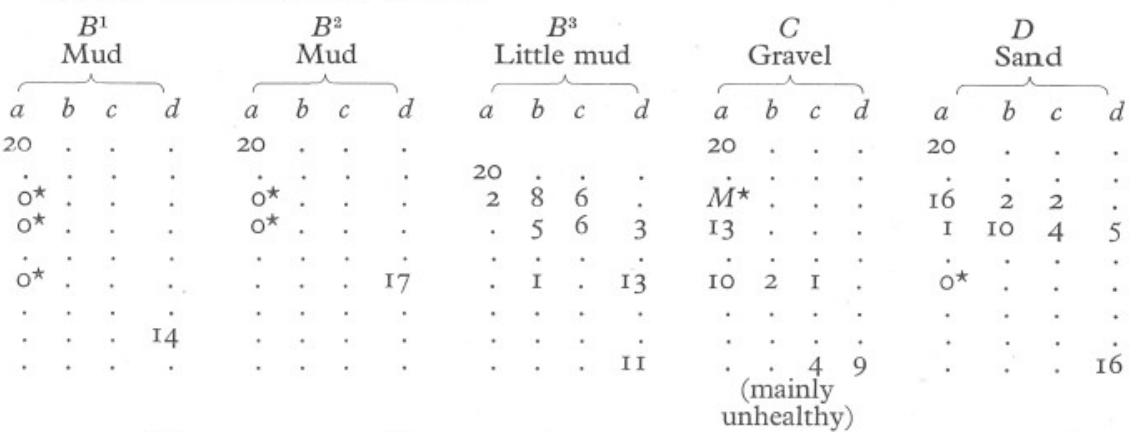

20

.. .5

$\begin{array}{llll}16 & 2 & 2\end{array}$

$0^{\star}$

i*

I3 
when spread out in a very thin layer. Three flat-bottomed glass dishes, $4.5 \mathrm{~cm}$. in diameter, were partially filled with about 18 c.c. filtered sea water. One was a clean control, one contained a fairly large quantity of mud in heaps on the bottom, while the third had a very little mud scattered thinly so that it was nowhere deep enough for larvae to burrow. The results show that in the latter dish the majority of the larvae continued to swim for a longer period than in the dish with much mud.

\section{TABLE IX}

(Exp. 9. Fertilization on May ro 1937)

\begin{tabular}{|c|c|c|c|c|c|c|c|c|c|c|c|c|}
\hline \multirow[t]{2}{*}{ Date } & \multicolumn{4}{|c|}{ Control } & \multicolumn{4}{|c|}{ Much mud } & \multicolumn{4}{|c|}{ Little mud } \\
\hline & $a$ & $b$ & $c$ & $d$ & $a$ & $b$ & $c$ & $d$ & $a$ & $b$ & $c$ & $d$ \\
\hline I7. v. 37 & 20 & & . & . & 20 & . & . & . & 20 & . & . & . \\
\hline I 8. v. 37 & I4 & 6 & . & . & $2^{\star}$ & . & . & . & I4 & $2^{\star}$ & . & . \\
\hline 19. v. 37 & I6 & 4 & . & . & $I^{\star}$ & . & . & . & II & $2^{\star}$ & . & . \\
\hline 20. v. 37 & 12 & 8 & . & . & $I^{\star}$ & . & . & . & $5^{\star}$ & $\dot{0}$ & . & . \\
\hline 21. v. 37 & IO & 10 & $\cdot$ & . & $0^{\star}$ & . & . & . & 2 & $5^{\star}$ & . & · \\
\hline 22. v. 37 & 7 & $1 \leftarrow 13$ & $\vec{M}$ & . & $0^{\star}$ & . & - & - & $0^{\star}$ & $\cdot$ & $\cdot$ & - \\
\hline 24 . v. 37 & (som & ae unl & & lthy) & - & - & - & - & - & . & . & - \\
\hline 26. v. 37 & (dea & id an & d dy & fing) & - & - & - & - & . & . & - & - \\
\hline
\end{tabular}

Exp. Io. During the progress of the last three experiments a clean fingerbowl containing several hundreds of larvae from the same fertilization was kept on the bench alongside. Temperature conditions would be identical with those in the experimental dishes, but the bowl was nearer to the window (north) and received a little extra light. It is interesting to give the records for this bowl which was examined from time to time after the first few days. No counts were made, but rough proportions were easily estimated. These records (Table $\mathrm{X}$ ) should be compared with the counts made on corresponding dates in Exps. 7, 8 and 9, because the finger-bowl can be regarded as a major clean control. It followed closely the course of the experimental controls with a tendency to slightly more advanced development, perhaps because of the greater crowding. These larvae were, however, definitely delayed in their development compared with those in the mud and sand dishes.

On May 20, about 4 days after the majority of the larvae provided with mud or sand had begun to metamorphose, it was decided to test some of the larvae still swimming freely in this finger-bowl. Accordingly twenty were picked out and placed in a dish containing mud. Most of them, if not all, metamorphosed. A count on May 28 gave seventeen worms, fifteen of them in excellent health, but two not so well, one being definitely abnormal. Three could not be found; it is possible they were missed but they might have been dead. Their deaths, however, would not alter the conclusion that the majority of the larvae can metamorphose normally several days after the time at which this first becomes possible and that their health is not adversely affected by the delay.

Exp. I I. This was a simple test to show what effect, if any, darkness would have on larvae kept in a clean control dish. On May I9 twenty swimming 
larvae from the finger-bowl were put into such a dish which was then kept in a light-tight box except for the few minutes whenever it was examined. The development of the larvae followed closely that of those in the other controls; there was, perhaps, a slight tendency to delay. This was not, however, sufficiently marked to be significant. It will be remembered that in Exp. 5 the tendency was in the opposite direction.

\section{TABLE X}

(Exp. Io. Fertilization on May Io 1937)

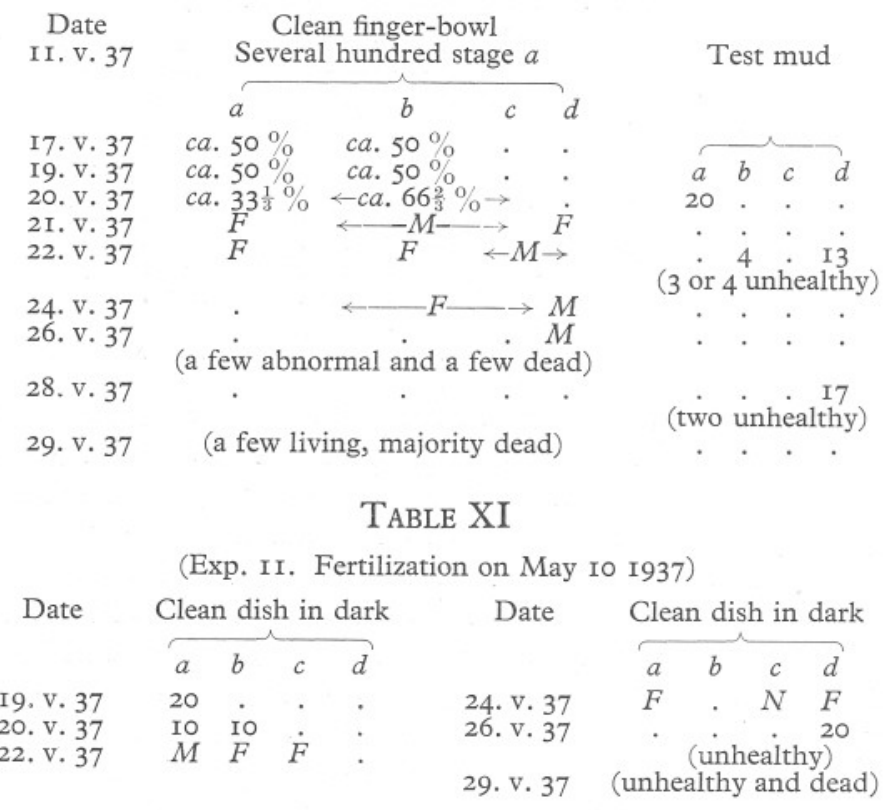

\section{Discussion OF THE RESULTS}

A consideration of the results leaves no doubt that Notomastus larvae will settle and metamorphose sooner when provided with mud or sand than when kept in perfectly clean glass vessels, other conditions being uniform. It seems fairly clear also that larvae will settle much more readily into mud or sand than into clean gravel, the latter being a soil in which the adults are not found. This is seen clearly in Exps. 7 and 8, and to some extent in 2, 3 and 4 where the gravel was probably not washed quite so clean as in the 1937 experiments. Exp. 5, however, is an exception to this, although the difference may be more apparent than real in that the gravel was not searched and that some of the larvae at any rate may have been swimming in the interstices. It will be remembered, too, that in this experiment the swimming of the larvae in the mud dish was unduly prolonged. 
The adults are found much more commonly in soft mud than in sand. It was thought that a distinct preference for the former would be shown, but the results are not very definite on this point. Exps. I, 2, 4 and 8-and on the whole 3 - seem to show such a preference, but Exps. 7 and 5 taken alone would indicate a liking for sand before mud, although it will be admitted that this preference is not at all strongly shown, and Exp. 5 is in any case an exception to the series in some respects. Taking all the experiments into consideration it may perhaps be said that larvae will generally settle a little more quickly into mud than into sand, but that the difference in effect between the two soils is not at all great.

Growth of the young worms between metamorphosis and the stage at which they normally begin to feed was generally much better in the mud and sand vessels than in the clean controls, where they usually soon became unhealthy and died. The same thing happened as a rule in the clean gravel where events on the whole followed closely the sequence of the controls. In mud or sand worms would be in excellent health several days after metamorphosis. In these soils also absorption of the yolk was in advance of that in the controls; thus in Exp. 8 it was nearly all absorbed by May 27 and 28 in the worms living in sand or mud, whereas the not very healthy worms in the controls had a fair quantity left. Moreover, the former had by that time six chaetigers, while the control worms had only five. In the mud the worms were on those dates beginning to swallow debris, although in the sand they were eating little or nothing, probably because the fragments were too large and no organic debris was present.

With the Mitraria larva of Owenia it was discovered (Wilson, I932) that a mere sprinkling of sand grains was sufficient to bring about metamorphosis, although the time taken to begin this after supplying the grains was much longer than when a fairly thick layer was given. Similarly for Notomastus, Exps. 7 and 9 have shown that a slight sprinkling of mud is effective in producing metamorphosis in advance of the clean controls, but at a longer interval of time than when the mud lies thickly. Exp. 8 shows, so it would seem, that it is only necessary for the mud to be deep enough for the larvae to bury themselves; the total quantity may be very small indeed. After metamorphosis the worms live as healthily as do those in thicker mud, even when it is very thinly scattered as it was in dish $B^{3}$ of Exp. 7 .

The influence, if any, of light is not at all clear. The experiments give hopelessly inadequate and contradictory data on this point; only further work can show whether light has any influence at all.

Further experiments might also be done to find out the effect of artificial soils of various substances and of differing grades. This perhaps would establish whether the effect is caused merely by particle size or whether there is in natural muds and sands, even after boiling, something of a more subtle and at present indefinable nature.

We have seen definitely that larvae provided with mud or sand metamorphose earlier than do those without it. Exp. Io has shown also that larvae 
which have been swimming in a clean vessel for some days longer than they would have done had a suitable bottom soil been available, will metamorphose if given such a soil and will continue normal healthy development. Thus there is in the larval life of this species a period of 2 or 3 days at least during which it can at any time settle and metamorphose. Under natural conditions this must be of very great value to the larvae when they are drifted along by tidal and other currents and come into contact with bottom soils of varying grade. It is possible for them to enter a soil and if it be not suitable to come out again. In the Notomastus experiments this often happened; it was also observed with Scolecolepis (Day \& Wilson, 1934). The larvae are likely to be in the bottom layers during the last free-swimming stage; at any rate in the plunger-jars and finger-bowls they then keep down close to the bottom, in contrast with the earlier stages which crowd up to the surface.

If a selective power on the part of larvae and an ability to metamorphose at any time during a fairly long period were eventually found to be general for bottom-living forms-especially those sharply restricted as to the nature of the soil in which they live-we should have advanced in our understanding of the means by which species are distributed. There would, it is true, remain other aspects of the problem to be taken into consideration. Scolecolepis larvae, for instance, select mud, but how do they find their right level on the shore? To that extent, perhaps, their settling may be pure chance, unless it happens that they are most strongly attracted to mud inhabited by the adults. We may be sure, however, that a power of selection would not eliminate all risks, shore forms would still be in danger of being swept out to deep water and lost, while larvae might never be drifted over the right kind of soil. Nevertheless, it would lessen very materially the dangers inherent in the possession of pelagic larvae, and the wastage in reproduction.

\section{SUMMARY}

The question is raised how pelagic larvae of marine bottom animals reach a type of substratum suitable for adult life. Attention is drawn to a few forms in which it is not entirely due to chance, since their larvae have been shown to exercise some degree of choice of the soil on which they will settle, and to be capable of preserving the ability to metamorphose for several days at least. These powers, if found to be fairly general in marine bottom animals, would have important bearings on distribution problems. There is supporting evidence from the investigations of Notomastus latericeus Sars here described. The adult is found in mud or muddy sand. Experiments showed that larvae of this species if provided with mud or sand generally metamorphose several days before those kept in clean glass vessels or with clean shell gravel. Mud perhaps induces slightly more rapid settling than sand. After metamorphosis the growth and health of the young worms is generally much better in mud or sand than in gravel or clean glass vessels. 


\section{REFERENCES}

Davis, F. M., I923. Quantitative studies on the fauna of the sea bottom. No. I. Preliminary investigation of the Dogger Bank. Min. Agric. Fish., Fish. Invest., Ser. II, Vol. vI, No. 2, pp. I-54.

DAY, J. H. \& WILSON, D. P., I934. On the relation of the substratum to the metamorphosis of Scolecolepis fuliginosa (Claparède). Fourn. Mar. Biol. Assoc., Vol. xIx, pp. 655-62.

Grave, G. \& WOODBRIDGE, H., I924. Botryllus schlosseri (Pallas): The behaviour and morphology of the free-swimming larva. Fourn. Morph., Vol. 39, pp. 207-47.

Lebour, M. V., I93I. The larval stages of Nassarius reticulatus and Nassarius incrassatus. Fourn. Mar. Biol. Assoc., Vol. xvil, pp. 797-818.

- 1933. The larval stages of Erato voluta (Montagu). Fourn. Mar. Biol. Assoc., Vol. xviII, pp. 485-90.

- 1933. The eggs and larvae of Philbertia gracilis (Montagu). fourn. Mar. Biol. Assoc., Vol. xviII, pp. 507-I0.

- I934. Rissoid larvae as food of the young herring. The eggs and larvae of the Plymouth Rissoidae. Fourn. Mar. Biol. Assoc., Vol. xIx, pp. 523-39.

- I 1934. The eggs and larvae of some British Turridae. Fourn. Mar. Biol. Assoc., Vol. xIx, pp. 54I-54.

- 1936. Notes on the eggs and larvae of some Plymouth prosobranchs. Fourn. Mar. Biol. Assoc., Vol. xx, pp. 547-65.

PrytherCH, H. F., I934. The role of copper in the setting, metamorphosis, and distribution of the American oyster, Ostrea virginica. Ecological Monographs, Vol. 4, pp. 47-I07.

VISSCHER, J. P., I928. Reactions of the cyprid larvae of barnacles at the time of attachment. Biol. Bull., Vol. LIV, pp. 327-35.

VISSCHER, J. P. \& LUCE, R. H., I928. Reactions of the cyprid larvae of barnacles to light with special reference to spectral colors. Biol. Bull., Vol. LIV, pp. 336-50.

Wilson, D. P., I932. On the Mitraria larva of Owenia fusiformis Delle Chiaje. Phil. Trans. Roy. Soc., Ser. B, Vol. 22I, pp. 23I-334.

- I933. The larval stages of Notomastus latericeus Sars. Fourn. Mar. Biol. Assoc., Vol. xvili, pp. 5II-I8.

- 1936. The development of the sabellid Branchiomma vesiculosum. Quart. Fourn. Micro. Sci., Vol. 78, pp. 543-603.

Yonge, C. M., I937. The biology of Aporrhais pes-pelecani (L.) and A. serresiana (Mich.). Fourn. Mar. Biol. Assoc., Vol. xxI, pp. 687-703. 